УДК 616.71-001.5-089.84]-06

DOI 10.17816/pmi3535-8

\title{
ПОСЛЕОПЕРАЦИОННЫЕ ОСЛОЖНЕНИЯ
}

МЕТАЛЛООСТЕОСИНТЕЗА КОНЕЧНОСТЕЙ

\author{
В.А. Самарцев ${ }^{1}$, И.В. Кадынщев ${ }^{1 *}$, Е.Г Волужсенков ${ }^{2}$ \\ ${ }^{1}$ Пермский государственный медицинский университет им. академика Е.А. Вагнера, \\ ${ }^{2} \mathrm{OOO}$ «Техническая диагностика», г. Пермь, Россия
}

\section{POSTOPERATIVE EXTREMITY METALLOSTEOSYNTHESIS COMPLICATIONS}

\author{
V.A. Samartsev ${ }^{1}$, I.V. Kadyntse ${ }^{1 *}$, E.G. Voluzbenkov ${ }^{2}$ \\ ${ }^{1}$ Academician Ye.A. Vagner Perm State Medical University, \\ ${ }^{2}$ Ltd. "Technical Diagnostics", Perm, Russian Federation
}

\begin{abstract}
Цель. Произвести качественный анализ металлического имплантата, погруженного в кость, определить тактику лечения при воспалительном процессе в послеоперационном периоде металлоостеосинтеза.

Материалы и методы. Проведен анализ лечения 1325 больных с развившимся посттравматическим остеомиелитом верхних и нижних конечностей за 10 лет (с 2004 по 2014 г.) в отделении осложненной травматологии ГКБ № 6 и травматологических отделениях г. Перми.

Результаты. Металлоз отмечен у 227 (17,2 \%) человек, он проявлялся нагноением и образованием свища в области винта через 2-3 месяца после оперативного лечения перелома у 177 (76,3 \%) больных, а у 50 (27,7 \%) пострадавших имел вид острого гнойного воспалительного процесса непосредственно после операции. У 34 (15 \%) пациентов при исследованиях с помощью компьютерной и магнитно-резонансной томографии отмечены вкрапления металла в кость. Всем этим 227 (17,2 \%) больным были удалены металлоконструкции. Послеоперационные раны после удаления металлоконструкций с кости зажили первично у 152 (66 \%) пациентов; вторичное заживление отмечено у 75 (44 \%) человек. Отдаленные результаты изучены в течение трех лет у 189 (83\%) человек.

Развитие послеоперационного остеомиелитического процесса, связанное с поздним удалением металлоконструкции, наблюдалось у 8 (4,4 \%) человек; образование ложного сустава - у 1 (0,5 \%) больного с переломом большеберцовой кости. Хороший отдаленный результат достигнут у 180 (95,2\%) человек.

Выводы. Своевременно поставленный диагноз, правильно выбранный метод лечения позволяют обеспечить полное восстановление структуры и функции и тем самым добиться положительной медицинской и социальной реабилитации данной категории больных.
\end{abstract}

ключевые слова. Остеомиелит, металлоостеосинтез, переломы конечностей, металлоз.

(с) Самарцев В.А., Кадынцев И.В., Волуженков Е.Г., 2018

тел. +79058641983

e-mail: kadyncevigor@mail.ru

[Самарцев В.А. - доктор медицинских наук, профессор, заведующий кафедрой общей хирургии № 1; Кадынцев И.В. ("контактное лицо) - кандидат медицинских наук, доцент кафедры общей хирургии № 1; Волуженков Е.Г. генеральный директор]. 
Aim. To carry out the qualitative analysis of metal implant, inserted into the bone, determine tactics for treatment of inflammatory process in the postoperative period of metallosteosynthesis.

Materials and methods. The treatment of 1325 patients with the developing posttraumatic osteomyelitis of the upper and lower extremities in the Department of Complicated Traumatology of City Clinical Hospital № 6 and traumatology departments of Perm for 10 years (2004-2014) was analyzed.

Results. Metallosis was observed in $227(17.2 \%)$ persons. Matallosis was manifested by suppuration and fistula formation in the region of screw 2-3 months after operative treatment of fracture in $177(76.3 \%)$ patients, and in $50(27.7 \%$ ) patients - by acute purulent inflammatory process immediately after the surgery. In 34 (15\%) patients, computed tomography and MRI demonstrated metal bone impregnations. All these 227 $(17.2 \%)$ patients underwent elimination of metal constructions. The postoperative wounds after elimination of metal constructions healed primarily in $152(66 \%)$ patients. Secondary healing of the postoperative wounds was noted in 75 (44 \%) persons. The long-term results were studied during 3 years in 189 (83\%) patients. The development of the postoperative osteomyelitic process, connected with late removal of metal construction, was registered in 8 (4.4\%) persons. False joint was formed in 1 (0.5\%) patient with tibial fracture. Positive long-term result was reached in 180 (95.2 \%) persons.

Conclusions. Timely diagnosis, correctly chosen technique of treatment permit to provide full restoration of the structure and function, and obtain positive medical and social rehabilitation in this category of patients.

Key words. Osteomyelitis, metallosynthesis, extremity fractures, metallosis.

\section{ВВЕДЕНИЕ}

За последние годы увеличивается число гнойных осложнений при оперативном лечении закрытых переломов, что связано с расширением показаний к металлоостеосинтезу конечностей. Основная часть этих ошибок (60,3 \%) зависит от неправильного подбоpa металлических конструкций, нарушений принципов асептики, оперативно-технических ошибок при выполнении операции, несоблюдения принципов правильной послеоперационной иммобилизации конечности. Попрежнему остается высокой частота неудовлетворительных результатов лечения (42-50 \%) и рецидивов воспаления костной ткани $(22-74,3 \%)[2,4,5,7,8,12,17]$. В связи с этим пациенты нередко подвергаются неоднократным оперативным вмешательствам, оставаясь неизлеченными десятки лет. Более 70 \% больных посттравматическим остеомиелитом на длительное время являются нетрудоспособными, из них почти 90 \% впоследствии становятся инвалидами, и это при том, что чаще всего заболевание поражает лиц мужского пола и преимущественно трудоспособного воз- раста $[6,8,10-13]$. Сегодня широко внедряется в практику остеосинтез с применением различных металлоконструкций при лечении изолированных закрытых переломов длинных костей [8] и при политравме [1]. Совершенствование, разработка и внедрение новых материалов, менее травматичных технологий, тем не менее, не привело к снижению количества послеоперационных осложнений в целом.

В связи с расширением показаний к остеосинтезу с применением металлоконструкций при оперативном лечении закрытых переломов увеличивается число гнойных осложнений $[3,8,10,12]$. Частота возникновения послеоперационного остеомиелита, по данным различных авторов, колеблется от 0,4 до 22,4\% [9, 10, 13, 15].

Основными материалами, используемыми для изготовления имплантатов, являются металлические сплавы (титановые, кобальтовые, нержавеющие стали), полимеры и керамика. Несмотря на интенсивный рост использования в имплантируемых изделиях полимеров и керамических материалов, металлические материалы все же преобладают (около 60 \% всех имплантатов). Изделия из 
сплавов стали марки ВТ6 используются примерно в 28 \% случаев.

Цель исследования - произвести качественный анализ структуры металлического имплантата, погруженного в кость, определить тактику лечения при воспалительном процессе в послеоперационном периоде металлоостеосинтеза.

\section{МАТЕРИАЛЫ И МЕТОДЫ ИССЛЕДОВАНИЯ}

Произведен анализ лечения 1325 больных с развившимся посттравматическим остеомиелитом верхних и нижних конечностей за 10 лет (с 2004 по 2017 г.) в отделении осложненной травматологии ГКБ № 6 и травматологических отделениях г. Перми.

Металлоз как начальное проявление послеоперационного остеомиелита отмечен у 227 человек (17,2 \%). Он проявлялся нагноением и образованием свища в области винта через 2-3 месяца после оперативного лечения перелома у 177 (76,3 \%) больных, у 50 (27,7 \%) пострадавших имел вид острого гнойного воспалительного процесса непосредственно после операции.

У 34 (15\%) пациентов с повреждениями верхних и нижних конечностей на компьютерной и магнитно-ядерной томографии отмечены вкрапления металла в кость. Всем этим больным были удалены металлоконструкции.

У 30 (60 \%) после удаления металлоконструкции с целью стабилизации перелома применен внеочаговый остеосинтез аппаратами внешней фиксации.

Мы провели анализ химического состава пластин и винтов, удаленных из большеберцовой, плечевой костей.

Анализ химического состава материала проводили в сердцевине и на поверхности образцов с использованием растрового электронного микроскопа РЭМ-100У с все- волновым дисперсионным анализатором спектра рентгеновского излучения ВДАР-1. Было представлено 8 образцов.

Пластины марки ВТ6 (новые) имели состав: титан - основное вещество, алюминий 5,8/5,9 нм (поверхность и основа), ванадий 4,5/4,5 нм, железо - 0,3/0,3 нм, кремний 0,1/0,1 HM.

\section{Результаты}

Удаленные пластины с поверхности подвергшихся нагноению переломов костей конечностей (марки медицинской стали ВТ6) имели следующий состав: титан - основное вещество, алюминий - 3,9/2,8 нм, марганец 1,3/1,2 нм, железо - 0,4/0,1 нм, кремний 0,1/0,1 нм, на поверхности пластины кальций - 0,3 нм, хлор - 0,2 нм, сера - 0,1 нм.

Винт самонарезной из стали марки ВТ6 (новый) включал: титан - основное вещество, алюминий - 5,7/5,4 (поверхность и основа), ванадий - 4,2/4,1, железо - 0,3/0,2, кремний $-0,1 / 0,1$.

Удаленные винты (ВТ6) состояли из: титана - основное вещество, алюминия 4,0/3,6 нм, ванадия - 2,9/2,9 нм, железа 0,7/0,2 нм, кремния - 0,1/0,1 нм, на поверхности пластины кальций - 0,2 нм, хлор 0,1 нм, сера - 0,1 нм.

Послеоперационные раны после удаления металлоконструкций с кости зажили первично у 152 (66 \%) пациентов. Вторичное заживление послеоперационных ран отмечено у 75 (44 \%) человек. Отдаленные результаты изучены в течение трех лет у 189 человек.

Развитие послеоперационного остеомиелитического процесса отмечено у 8 (4,4 \%), оно связано с поздним удалением металлоконструкции. Образование ложного сустава наблюдалось у 1 (0,5 \%) человека. Хороший результат достигнут у 180 (95,2 \%) пациентов. 


\section{Выводы}

Сравнительный качественный химический анализ имплантатов показал, что имплантат (металлическая пластина или винт), погруженный в кость, подвержен отторжению - металлозу - за счет отложения кальция, хлора, серы на его поверхности. Это зачастую может приводить к замедленной консолидации переломов и развитию послеоперационного остеомиелита конечностей.

Своевременное удаление металлоконструкций, комплексное лечение в условиях специализированного отделения, удаление металлоконструкций от 1-3 дней при появлении свищевых ходов к области винта и комплексное лечение в условиях специализированного отделения привели к полному выздоровлению 95,2 \% больных.

Своевременно поставленный диагноз, правильно выбранный метод лечения позволяют обеспечить полное восстановление структуры и функций и тем самым добиться положительной медицинской и социальной реабилитации данной категории больных.

\section{БИБЛИОГРАФИЧЕСКИЙ СПИСОК}

1. Болтенков В.К., Куликов А.Н., Литвинов С.Д., Тетюшкин С.Н. и др. Алгоритм лечения посттравматического остеомиелита. Материалы Всерос. науч.-практ. конф. с междунар. участием, посвящ. памяти профессора А.Н. Горячева. Омск: Полиграф 2011; 115.

2. Гринев М.В. Остеомиелит. Л.: Медицина $1977 ; 152$.

3. Грязнухин Э.Г. Гнойные осложнения полифрактур и профилактика остеомиелита. Хронический остеомиелит: сб. науч. тр. Л. 1982; 53-59.

4. Дзюба Г.Г., Резник Л.Б. Разработка универсальных подходов к лечению остеомиелитов длинных костей скелета на основе опорных локальных антибактериальных носителей. Вестник травматологии и ортопедии им. Н.Н. Приорова. М. 2016; 1: 26-31.

5. Исайкин А.А, Хамяков Н.В., Фарыгин В.А. Лечение хронического остеомиелита у больных с обширными травматическими дефектами голени. Сб. тез. ІХ Съезда травматологов-ортопедов. Саратов: Научная книга 2010; 3: 1059-1060.

6. Котельников Г.П., Яиков А.В. Гравитационная терапия в коррекции нарушений репаративного остеогенеза. Самара 2000; 208.

7. Линник С.А., Назаров Х.Н., Мирзоев Р.P. Эффективность иммуномодулирующей терапии хронического остеомиелита у больных с сочетанными и множественными травмами нижних конечностей. Человек и его здоровье: Второй Всерос. конгр. по травматологии с междунар. участием. СПб. 2017; 50-51.

8. Мироманов А.М., Трубицин М.В. Персонализированные аспекты развития восполительных осложнений при переломах костей конечности. Политравма. ЛенинскКузнецкий 2017; 37-41.

9. Никитин Г.Д., Рак А.В., Линник С.А. Хирургическое лечение остеомиелита. СПб.: Русская графика 2000; 288.

10. Рушай А.К. Значимость факторов в выборе лечебной тактики у больных с остеомиелитом конечностей. Травма 2016; 17 (3): 155-158.

11. Столяров С.А., Бадеян В.А. Диагностика хронического остеомиелита конечностей на фоне его местных гнойных осложнений в неспециализированных течебно-профилактических учреждениях. Самара 2017; 27 (3): 44-47.

12. Al-Mudhaffar M., Prasad C.V., Mpfidi A. Wound complications following operative fixation of calcaneal fractures. Injury 2000; 31 (6): 461-464.

13. Flemister A.S. Jr., Infante A.F., Sanders R.W., Walling A.K. Subtalar arthrodesis for complications of intra-articular calcaneal fractures. Foot Ankle Int 2000; 21 (5): 392-399.

Материал поступил в редакцию 12.03 .2018 